\title{
Fostering Artistic Ensemble Performance Exploring the Role of Transformational Leadership
}

\section{Sabine Boerner, ${ }^{1}$ Diether Gebert ${ }^{2}$}

${ }^{1}$ University of Konstanz, ${ }^{2}$ Renmin University of China

Although empirical studies suggest that a transformational leadership style is efficient in orchestras, a coherent explanation for this finding is lacking. Linking research on workforce diversity with research on team innovation, this article provides a framework that explains the positive effects of transformational leadership in orchestras. Transformational leaders enhance the positive effects of ensemble diversity on idea generation, while at the same time reducing its negative effects on idea integration. This twofold effect of transformational leadership promotes artistic ensemble performance, that is, a coherent, highly synchronized interpretation of a given score. Contributions to the literature and implications for further research are formulated.

Keywords: transformational leadership, ensemble diversity, creativity, orchestra

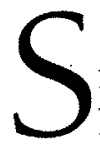
tudies on the leadership behavior of orchestral conductors are rare (Boerner, 2009; Hunt, Stelluto, and Hooijberg, 2004). However, all existing empirical studies of leadership in orchestras agree with the finding that transformational, visionary, and charismatic leadership styles are efficient in this context (Atik, 1994; Boerner, Krause, and Gebert, 2004; Boerner and von Streit, 2005; Mintzberg, 1998). Since leadership research has identified a wide range of leadership styles (Avolio, Walumbwa, and Weber, 2009; Yukl, 2006) that might be relevant in the orchestral context, this result is striking. Still, a coherent explanation for this finding

Correspondence to: Sabine Boerner, University of Konstanz, Fach 88, Universitaetsstrasse 10, 78457 Konstanz, Germany. E-mail: Sabine.Boerner@uni-konstanz.de 
is lacking. To address this gap, we developed a framework for explaining the positive effects of transformational leadership in orchestras.

Several studies have provided evidence for the positive effects of a conductor's transformational leadership style. Atik (1994) focuses on the interactive dynamics between conductor and orchestral musicians. By conducting interviews with (former) players and conductors from three major orchestras in the United Kingdom, he identifies three sequential stages of the leader-follower relationship in the orchestra: the testing phase, the working phase, and the inspirational phase. In the testing phase, musicians and conductor mutually explore their relationship. "Players explore the boundaries of the superior-subordinate relationship and the professional competence of the conductor, while, simultaneously, the conductor tests out how much he can demand of his players and the musical capabilities of the "band"' (p. 26). In the working phase, the relationship is characterized as "transactional," meaning that mutual expectations have been worked out and both musicians and conductor are "task oriented in achieving what is required" (p. 26). The inspirational stage is characterized by the conductor's charismatic or transformational leadership style. Apart from his or her natural authority, the charismatic conductor is described by the clarity of his or her message ("knowing what the conductor wants"; p. 26), his or her praise ("one of the ways that conductors can really open up this orchestra"; p. 26), and his or her ability to demand ("they want to feel that the conductor is getting their very best out of them"; p. 26).

After spending one day with the conductor of a large symphony orchestra, Mintzberg (1998) claims that leadership in orchestras is more about inspiration than about close supervision. In particular, charisma is an important characteristic of the conductor. In addition, Mintzberg observes two aspects of the conductor's leadership. First, the conductor uses "covert leadership," that is, "not leadership actions in and of themselves-motivating, coaching, and all thatbut rather unobtrusive actions that infuse all the other things a manager does" (p. 144). Second, an important aspect of leadership in orchestras is the building of culture. However, this leadership task is covert as well, since orchestras have an established cultural tradition.

Boerner and others (2004) investigate the conductor's leadership of orchestra musicians as a combination of authority and charisma. Analyzing a sample of 334 musicians from thirty professional German orchestras, the authors find the so-called directive-charismatic leadership style to have a positive impact on the quality of ensemble playing, thus promoting artistic quality. Boerner and von Streit (2005) investigate the degree to which the conductor's transformational leadership style (Bass and Riggio, 2006) and a cooperative climate in the orchestra favorably affect the orchestra's artistic quality. 
They define a cooperative climate by two dimensions: warmth and support (mutual estimation) and a high level of cohesion (absence of conflicts). The authors claim that a cooperative climate in the orchestra positively moderates the transformational leadershipperformance relationship. A study of 208 musicians from twentytwo professional German symphony orchestras confirms the assumed interaction effect of the conductor's transformational leadership style and the cooperative climate among the musicians on the orchestra's artistic quality.

Despite the agreement on the effectiveness of transformational leadership in orchestras, existing explanations for the effectiveness of a conductor's charismatic or transformational leadership are dispersed and inconsistent. Atik's (1994) explanation of the effectiveness of transformational leadership is focused on the interactive instead of the one-way nature of the relationship between musicians and conductor. Transformational leadership is interpreted as a "higher level relationship" (p. 6) resulting from the successful negotiation of the two preceding phases. Thus, transformational leadership includes sharing of responsibilities and diminishes hierarchical boundaries, leaving space for the musicians' future development. "Even follower free choice is present, at least in the sense that the player has agreed to be led or, as one musician put it, "We allow him to shout at us"' (p. 6). Mintzberg (1998) explains the effectiveness of charismatic leadership by the musicians' characteristics and by aspects of the leadership relationship. Given their high degree of qualification, orchestra musicians can be compared to knowledge workers, that is, highly trained and trusted professionals. Therefore, the conductor appears as the leader among ostensible equals. "A good symphony orchestra requires both highly trained professionals and clear personal leadership: if the players do not accept the conductor's authority or if the conductor does not accept the players' expertise, the whole system breaks down" (p. 145).

Boerner and others (2004) provide the following explanation for the effectiveness of directive-charismatic orchestral leadership. Due to the ambiguity of the score and the technical conditions in an orchestra, a centralized coordination instead of decentralized selfcoordination of orchestral playing is necessary. However, such directive leadership style might have a negative impact on the players' motivation. Therefore, the charismatic component of leadership is necessary, because it "induces musicians to accept restrictions on their individual freedom in the process of artistic production in the interest of a high artistic result, so they accept the target set by the conductor" (p. 469). Similarly, Boerner and von Streit (2005) ascribe the efficiency of transformational leadership in the orchestral context to the positive impact on musicians' individual motivation. However, they claim that this effect is contingent on the climate within the orchestra. Because a close synchronization of all musicians is 
required, transformational leadership will enhance orchestral performance only if the climate is cooperative.

The more or less explicit explanations for the effectiveness of transformational leadership in the orchestral context focus on diverse particularities of this context. Despite their diversity, these explanations have two things in common. First, they focus mainly on the individual level of the musicians. Albeit processes on the aggregate level such as cooperation and cooperative climate are mentioned (Boerner and others, 2004; Boerner and von Streit, 2005), they have not been analyzed in detail. Second, the outcome of leadership in orchestras has not been systematically included in the explanations provided.

Against this background, we provide a comprehensive theoretical explanation for the effectiveness of transformational leadership in orchestras. We explicitly focus on the aggregate level of the artistic ensemble rather than the individual musician level.

First, we analyzed prominent features of the process of ensemble performing. To achieve high levels of artistic performance-that is, a coherent, synchronized interpretation of a given score-individual artistic creativity has to be transformed into collective creativity. Creative individual input must be integrated into a creative joint output. Leaders in orchestras must find ways to balance the individual musicians' needs for autonomy and artistic self-realization with the orchestra's goal of achieving a high-quality joint performance. Because of the nature of the orchestra workforce, transforming individual artistic creativity into collective creativity is challenging. Musicians tend to be pronounced individualists (Feist, 1999; Feist and Gorman, 1998). Even rank-and-file musicians, who, by and large, are expected to follow the conductor's interpretation, are generally trained to become soloists (Atik, 1994; Mintzberg, 1998). Because transformational leaders understand the necessity of change, encourage new and fresh ways of looking at problems, and act as role models for creativity by displaying unconventional and innovative behavior (Eisenbeiss, van Knippenberg, and Boerner, 2008), transformational leadership may prove to be a promising approach.

Second, we considered structural features of ensemble performance. Orchestral musicians differ in instrument category, artistic profile, professional experience, gender, nationality, and age (Couch, 1983). Hence, workforce diversity (Williams and O'Reilly, 1998) appears particularly relevant in this context. Results from research on organizational diversity indicate that members' diversity can be either an opportunity for or a barrier to team creativity (Milliken and Martins, 1996; van Knippenberg, De Dreu, and Homann, 2004; Williams and O'Reilly, 1998).

Tying back to insights in organizational creativity and innovation, we explicitly investigated artistic production in orchestras in 
Figure 1. The Role of Transformational Leadership in the Performing Arts

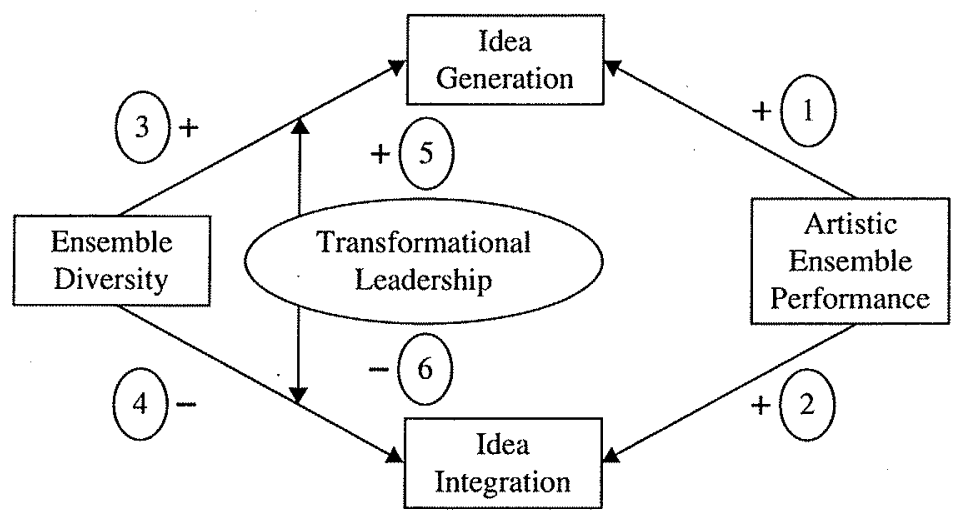

terms of idea generation and idea integration (compare Hunt and others, 2004; Sheremata, 2000). First, we analyzed how these processes are affected by the level of workforce diversity in orchestras. To understand the beneficial effects of transformational leadership in orchestras, we explored the role of transformational leaders in the context of ensemble diversity.

This article provides a theoretical explanation for the beneficial effects of transformational leadership in orchestras. This explanation may provide a coherent theoretical framework through which to interpret existing empirical findings. Moreover, the explanation may be generalized to other organizational contexts where creativity is required under the condition of workforce diversity. Thereby, the previously scarcely considered role of transformational leadership in the diversity-creativity relationship can be further investigated.

\section{An Integrated Framework: Transformational Leadership in Orchestras}

We developed a framework (presented as Figure 1) that specified the role of transformational leadership in orchestras. From this framework, we developed six propositions. First, we introduced idea generation and idea integration as predictors of artistic ensemble performance. Second, we investigated the effects of ensemble diversity on idea generation and idea integration. We assumed that musicians' diversity is likely to positively affect the process of idea generation but negatively affect the process of idea integration. Third, we investigated the beneficial role of transformational leadership for the artistic performance of diverse orchestras. 


\section{The Process of Artistic Interpretation in Orchestras}

Although a symphony orchestra performs a given work, the joint interpretation of this work is an inherently creative task (for example, Boerner and von Streit, 2005; Hunt and others, 2004; Vredenburgh and $\mathrm{He}, 2003)$. Creativity is one of the prominent features of the artistic production process in orchestras. The processes that must be closely coordinated in orchestras can be analyzed by examining research on organizational creativity and innovation (compare Hunt and others, 2004). According to Sheremata (2000), creative organizational processes include two processes: idea generation and idea integration. Idea generation refers to the creative process of jointly developing new and useful ideas. Musicians generate ideas when they elaborate and discuss their individual conceptions about the interpretation of a score (Firlus, 2001). Idea integration describes the process of combining the suggested alternatives and transferring them into a joint interpretation concept. The more or less diverging individual ideas must be reconciled to achieve a coherent interpretation. Idea integration includes the joint evaluation of the different ideas and requires setting priorities and taking decisions. In the orchestra, musicians must agree on details of the musical interpretation, such as dynamic, articulation, and tempo, to achieve a highly synchronized performance.

Although the processes of idea generation and idea integration can be applied to the orchestral context (compare Hunt and others, 2004), they are different from the creative processes used by other organizational working teams. First, in the orchestra, the performance is determined by the score, by the degree to which the score can be interpreted, and by the sounds the audience is receptive to (Mintzberg, 1998). One could argue that the degree to which idea generation and idea integration are possible in orchestras is smaller than in other organizations. Nevertheless, every orchestral work leaves a broad range of details, such as tempo and articulation, to be interpreted. Indeed, exactly these freedoms in interpretation make for the attractiveness of live performances. The orchestra can thus be understood as a context "where new, creative, and even daring creative choices in interpretation" are required (Hunt and others, 2004, p. 158).

Second, because of the large size of orchestras and the broad range of alternatives for interpreting a given score, the processes of idea generation and idea integration in a symphony orchestra are organized in a different way than they are in most organizations. They are typically not organized in the form of an open discussion. Rather, the conductor presents interpretive vision and direction. However, musicians must creatively "respond to this vision and follow through with technical/expressive solutions" (Hunt and others, 2004 , p. 152). The conductor begins with what the musicians offer and continuously works on improving and shaping this offer (Hunt 
and others, 2004). This is particularly true for the soloist musicians of the orchestra. They have to develop individual ideas of how to interpret their parts. In the symphony orchestra, idea generation results from the interplay between the musicians' individual inspiration and the conductor's artistic conception: "It's this constant sort of interrelationship of ideas that makes the best music" (Atik, 1994, p. 5). The musicians "must solve creatively the individual technical issues in the music while remaining flexible and motivated enough to change artistic direction at the request of a conductor" (Hunt and others, 2004, p. 152). An interview with a conductor illustrates this active creative role of the musicians. "Sometimes, in a performance, you feel the phrasing taking off. And another player will respond in the same kind of way, phrasing the answer in the same way. And then another player. A group of players will take it up and performance will be created. You're just watching it happen" (Atik, 1994, p. 26).

Similarly, during the process of idea integration, individual ideas must be aligned with the overall conception of the interpretation of a composition. In a symphony orchestra, the conductor takes the final decision on the details of the interpretation. However, since idea integration occurs during the process of joint interpretation, the musicians take responsibility for the details of the coordination, such as joint movements (for example, of the string players) or joint breath taking (to realize a joint entrance of multiple instruments).

According to Sheremata (2000), idea generation and idea integration are complementary processes. Accordingly, any successful orchestral performance requires both. Idea integration is impossible if no creative ideas have been generated; similarly, generated ideas and alternatives must be integrated to result in coherent interpretations. The processes of idea generation and idea integration are thus mutually dependent and cannot compensate for each other (compare Gebert, Boerner, and Kearney, 2010). The challenge of accomplishing a well-coordinated artistic performance in orchestras translates into the problem of enabling and assuring both processes. Hence, high levels of both idea generation and idea integration in an orchestra will stimulate high levels of artistic performance.

Proposition 1: Idea generation will foster artistic ensemble performance.

Proposition 2: Idea integration will foster artistic ensemble performance.

\section{The Challenge of Diversity in Symphony Orchestras}

At first sight, orchestras may appear to be homogeneous groups. As trained professionals, orchestral musicians are likely to share technical vocabulary, professional culture, and knowledge. However, a 
closer look at symphony orchestras reveals a considerably high level of heterogeneity (Boerner and von Streit, 2005; Couch, 1983). Orchestra musicians differ, first of all, in their professional specializations, such as instruments or instrument groups (strings, wind, percussion). They tend to base their professional identities much more on their instrument categories or orchestral sections than on the orchestra as a whole (Boerner and von Streit, 2005). Since different instruments are popular within different social backgrounds, the primary socialization of a violinist can be considerably different from that of a brass player. Relatively stable subgroups are established in orchestras along instruments or instrument groups (Erd, 1987). Further, orchestral musicians differ in their levels of artistic virtuosity, professional experience, ensemble tenure, and hierarchical position within the ensemble (soloists versus rank-and-file members). Since career options within and between orchestras are usually limited (Faulkner, 1973), diversity in hierarchical positions is particularly relevant. Orchestra musicians also differ in demographic variables such as gender, age, nationality, culture, and ethnicity. Moreover, orchestra musicians, especially soloists, are often selected because of their artistic personalities and profiles. In sum, members of symphony orchestras are likely to differ not only in socalled surface-level or demographic diversity (for example, age, gender, nationality, tenure) but in deep-level diversity variables (for example, attitudes, personality, values) as well (compare Mohammed and Angell, 2004).

Research on the effects of team member diversity on the performance of work groups has yielded largely inconsistent results. Diversity has been found to entail positive as well as negative effects on team performance. In particular, diversity has been discussed as a promise for organizational creativity and innovation (Gebert, Boerner, and Kearney, 2006; van Knippenberg and Schippers, 2007; Williams and O'Reilly, 1998). Analyzed from the information and decision-making perspective (for example, Jackson, Joshi, and Erhardt, 2003; van Knippenberg and Schippers, 2007; Williams and O'Reilly, 1998), diverging ensemble members are likely to develop different viewpoints on how to interpret a given composition. Diverse points of view, for example, on how to interpret a certain part of the score, may offer the chance to develop a new and creative understanding of this particular part. Diversity may stimulate the process of idea generation because of the increased potential for ideas and perspectives articulated by diverse team members. While surface-level diversity dimensions are interpreted as indicators of team members' cognitive diversity (for example, Jackson, Brett, Sessa, Cooper, Julin, and Peyronnin, 1991), this effect is especially likely for members' deep-level diversity, such as different values, standpoints, and personalities. Diverging ensemble members are likely to develop different viewpoints on how to interpret a given 
work. Hence, diversity may stimulate the process of idea generation in orchestras due to the enlarged potential of ideas and perspectives.

Proposition 3: Diversity in an orchestra is positively related to the process of idea generation.

However, the similarity-attraction or social categorization perspective (for example, Turner, 1987) suggests possible risks of diversity in the process of orchestral production. Subgroups may develop in the ensemble, resulting in conflicts (Glynn, 1996) that may threaten cooperation and communication (Certo, Lester, Dalton, and Dalton, 2006). This in turn will impede the process of combining the suggested alternatives and transferring them into a coherent interpretation. The process of idea integration is jeopardized. A compelling example is the experience of the Orpheus Chamber Orchestra in its early years, which was characterized by heavy conflicts about the "right" interpretation (Firlus, 2001). This negative diversity effect is not only likely for attributes of surface-level diversity, but for deep-level diversity as well (Mohammed and Angell, 2004).

Proposition 4: Diversity in an orchestra is negatively related to the process of idea integration.

The role of workforce diversity in orchestras seems to be ambivalent (see Figure 1). Diversity in an orchestra may stimulate idea generation (arrow 3), which in turn will enhance orchestral performance (arrow 1). However, diversity in an orchestra may hinder idea integration (arrow 4). Thereby, a coherent joint interpretation is challenged. The positive impact of idea integration on ensemble performance (arrow 2) will no longer be fruitful. Because both idea generation and idea integration are necessary, orchestral performance is challenged.

\section{The Role of Transformational Leadership in Orchestras}

The specific feature of transformational leadership is a close personal relationship between the transformational leader and his followers (Bass and Riggio, 2006). Followers highly trust their leader, tend to admire him or her, and strongly identify with him or her. Thereby, followers' motivations and needs are transformed, resulting in exceptional efforts and performance "beyond expectations" (Bass, 1985). In Bass's conception, transformational leadership consists of four dimensions: (1) idealized vision (charisma), (2) inspirational motivation, (3) intellectual stimulation, and (4) individual consideration. Idealized influence refers to transformational leaders' charismatic role-modeling behavior (House, 1977). Followers trust and respect their leader because they accept him as a role model. As a consequence, they want to emulate him. Through inspirational motivation, transformational leaders develop and communicate an 
appealing vision for the team or the organization, thereby providing meaning to followers' work. Through intellectual stimulation, transformational leaders encourage followers to challenge existing assumptions, reframe problems, and approach old situations in new ways. Individualized consideration summarizes the leader's coaching and mentoring behaviors that take individual differences between followers into account. Although the four components of transformational leadership are designed to be conceptually different, there is empirical evidence for a high interdependence of these four components (Judge, Woolf, Hurst, and Livingston, 2006; Yukl, 2006). Empirical studies have confirmed the effectiveness of transformational leadership in different organizational contexts (Bass and Riggio, 2006; Dumdum, Lowe, and Avolio, 2002). Transformational leadership has been shown to enhance organizational creativity and innovation (for example, Bass and Avolio, 1994a; Cascio, 1995; Eisenbeiss and others, 2008).

Based on empirical evidence concerning orchestras and recent research on transformational leadership in diverse teams, we investigated the role of this leadership style in the relationship between ensemble diversity and artistic performance. A transformational leader may reinforce the positive effects of diversity on idea generation (see Proposition 3). Under high levels of transformational leadership, the positive effects of diversity on idea generation are more likely to occur. First, by idealized influence (charisma), the transformational leader serves as a role model for a creative interpretation of a given work. By communicating his vision for the interpretation, the transformationally leading conductor leaves some space for the musicians (Atik, 1994). Compared to traditional leadership styles, transformational leadership is more about emphasizing change and envisioning (Bass and Avolio, 1994a; House, 1977). "He'll communicate a point about something and from that point on, leave it up to the abilities that he knows the players have" (Atik, 1994, p. 26). Second, intellectual stimulation in the orchestral context means the interpretation of a familiar work in a novel way (Boerner and von Streit, 2005). This may directly stimulate the musicians' creativity (compare Bass and Avolio, 1994b; Bass and Riggio, 2006). Third, through individualized consideration, musicians are encouraged to express their individual ideas and thus make them fruitful for the process of idea generation (compare Bass and Avolio, 1994b; Bass and Riggio, 2006). This effect is underlined by the first dimension of transformational leadership, that is, charisma. According to House (1977), charismatic leaders communicate high performance expectations of and confidence in their followers. Interviews with musicians illustrate this motivating effect of transformational conductors. "It is using the very people that he has gathered around him ... to their very best advantage because they develop their own ideas about it. They help him make his music" (Atik, 1994, p. 26). 
Taken together, under high levels of transformational leadership the potential of ensemble diversity for joint idea generation is more likely to be realized. Transformational leadership will thus moderate the diversity-idea generation relationship.

Proposition 5: Transformational leadership will moderate the positive relationship between ensemble diversity and idea generation such that this relationship will be stronger under high levels of transformational leadership.

Moreover, a transformational leader seems capable of reducing the negative effects that diversity may have on the process of idea integration (see Proposition 4). Providing both a collective vision and inspirational motivation, transformational leaders may foster team spirit among the followers. This is especially true for the charismatic dimension of transformational leadership. According to House (1977), charismatic leaders create a collective sense of identity among followers. Empirical studies in the organizational context reveal that transformational leaders foster mutual trust among team members and contribute to collective team identification (for example, Kark and Shamir, 2002; Kark, Shamir, and Chen, 2003; Kearney and Gebert, 2009). As a result, a cooperative climate is established in the ensemble, which in turn is likely to alleviate communication and cooperation of the artists. Interviews with conductors confirm this effect for the orchestral context. "You have sometimes a hundred people, sometimes more, on the stage. . . I would say an energetic field, a psychological energy field which is very strong and has an existence of its own. And the conductor has to be forming that field and be part of it" (Atik, 1994, p. 27). Under high levels of transformational leadership, the negative effects of diversity on idea integration are reduced.

Proposition 6: Transformational leadership will moderate the negative relationship between ensemble diversity and idea integration such that this relationship will be lower under high levels of transformational leadership.

Transformational leadership is likely to reinforce the positive impact of diversity on idea generation while at the same time cushioning the negative effects of diversity on idea integration. Under high levels of transformational leadership, the positive effects of diversity are thus likely to outweigh its negative effects on the joint process of artistic production.

\section{Discussion}

While research has provided empirical evidence for the effectiveness of transformational leadership in orchestras, existing explanations for this effect are not consistent. Incorporating the research on both organizational creativity and workforce diversity, this article 
presents a coherent framework through which to explain the role of transformational leadership in orchestras. Transformational leadership is likely to reinforce the positive impact of ensemble diversity on the process of idea generation while at the same time cushioning the negative effects of ensemble diversity on the process of idea integration. The overall positive effect of transformational leadership on artistic performance in orchestras is explained by this twofold impact on the creative process in orchestras.

\section{Limitations}

First, our model does not include all possible predictors of the outcome variable "artistic ensemble performance." Apart from the processes of idea generation and idea integration and their determinants, a variety of additional factors, such as musicians' skill and pay, the quality of their instruments, and the acoustics of the premises, are clearly relevant to the artistic outcome. Hence, in an empirical test of our model (see Figure 1), we would not expect to completely explain the variance in the outcome variable.

Second, our model does not cover the full range of conductor behavior in an orchestra. Contingent on the legal and organizational structure of an orchestra, a conductor's leadership behavior is not limited to artistic leadership; it may include aspects of executive leadership such as decisions on recruitment and pay, concert tours, recordings, and marketing. However, since our model aims to explain the effectiveness of transformational leadership as confirmed in empirical studies, it is limited to transformational conductor leadership. Likewise, we do not address the notion of dual leadership, that is, artistic leadership and executive leadership of two or more leaders in orchestras. While the literature has examined the impact of conflicts rising from dual leadership on the performance of nonprofit performing arts companies (Reid and Karambayya, 2009), insights in these dynamics in the context of symphony orchestras are lacking.

These limitations of our model also help to prevent the problem of endogeneity (compare Antonakis and others, 2010; Hamilton and Nickerson, 2003). If the orchestra conductor determined the composition of the orchestra, then orchestra diversity and leadership style would both derive from the same source. It is possible that a third construct determines both the leadership style and the leader's decision to select (or not) a musician. However, because of the restriction on the conductor's transformational leadership style, endogeneity is not a problem in our model.

Third, our model is restricted to the moderating effect of transformational leadership in orchestras as illustrated in Figure 1. We focus on a group-level phenomenon and steer clear from traditional individual-level explanations. Alternate mechanisms that could 
explain the effect of transformational leadership in orchestras are briefly discussed below. Musicians' motivation is a central concept when explaining the effect of transformational leadership in the context of symphony orchestras (Boerner and von Streit, 2005). Although we argue that transformational leadership will compensate for motivational deficits of the musicians, the motivational effects of a transformational conductor can further be explained according to Shamir, House, and Arthur's (1993) self-concept theory of charismatic leadership. The motivational charismatic components suggested in this theory can well be applied to the orchestral context. First, the charismatic conductor stresses the intrinsic value of musicians' effort, for example, by addressing the musicians' self-concept and personal identity as members of a particular orchestra. Since mobility is very limited between orchestras, this issue is particularly relevant in the orchestral context. Second, a charismatic conductor will increase the musicians' sense of individual and collective selfefficacy, which is extremely relevant given the process of joint interpretation of a score. Third, a conductor's charismatic leadership style will enhance the intrinsic value of the musicians' goal accomplishment and their reward expectancies. A charismatic conductor is likely to communicate a mission or vision of the orchestra, which may carry forward the cultural traditions of each orchestra (Mintzberg, 1998).

\section{Contributions to the Literature}

The first contribution of the model developed in this article lies in a coherent explanation of the beneficial effects of transformational leadership in orchestras. The theoretical framework integrates the dispersed explanations in the literature, which are based on the musicians' space for development (Atik, 1994), the particularities of musicians and of the leader-follower relationship (Mintzberg, 1998), and musicians' motivation (Boerner and others, 2004; Boerner and von Streit, 2005). Although those explanations are limited to the level of the individual musicians, our approach focuses on the aggregate level of the artistic ensemble as a whole. Thereby, we systematically consider both the structure of the ensemble and the process of collective ensemble playing. Ensemble diversity is a prominent structural feature of orchestras. Although mentioned in several studies (Boerner and von Streit, 2005; Couch, 1983; Erd, 1987), diversity in orchestras has never been systematically connected to orchestra performance. However, according to the literature on team diversity (Milliken and Martins, 1996; van Knippenberg and others, 2004; Williams and O'Reilly, 1998), diversity in orchestras may have ambivalent effects on the process of collective ensemble playing. To achieve a high level of artistic performance in an orchestra, the creative input of the individual musicians must be transformed into the collective 
creativity of the orchestra. Inspired by research on organizational innovativeness (Sheremata, 2000), our model analyzes this transformation process in terms of idea generation and idea integration. While diversity will foster idea generation, it is likely to challenge idea integration. Since both processes are necessary to achieve high artistic performance, diversity in orchestras is likely to have ambivalent effects on the artistic performance.

Our model allows for a more complex explanation of the beneficial role of transformational leadership in orchestras than does the existing literature. First, it allows for identifying at which stage of the collective artistic process transformational leadership may exert beneficial effects. Transformational leadership moderates both the positive relationship between diversity and idea generation and the negative relationship between diversity and idea integration. Second, our model allows for identifying how transformational leadership may exert beneficial effects on the collective artistic process in orchestras. Although transformational leadership may reinforce the positive relationship between diversity and idea generation, it may cushion the negative relationship between diversity and idea generation. To the best of our knowledge, our model is the first to systematically combine features of orchestral structure and orchestral processes in order to explain the beneficial effects of transformational leadership in this context.

The second contribution of our model refers to the more generalized area of transformational leadership. Transformational leadership has been largely discussed as a promising approach in the context of team innovation and creativity. Nevertheless, empirical studies on the role of transformational leadership in team innovation or team creativity in general are rare and inconsistent (for example, Eisenbeiss and others, 2008). A positive relationship (for example, Keller, 1992, 2006; Sosik, Kahai, and Avolio, 1998), a negative relationship (for example, Jaussi and Dionne, 2003), and no relationship between transformational leadership and team innovation (for example, Waldman and Atwater, 1994) have been found. Scholars have therefore suggested placing more emphasis on the creative process when analyzing the beneficial effects of transformational leadership (for example, Yukl, 2006). However, to the best of our knowledge, the processes of knowledge generation and knowledge integration have never before been considered in this context. The model developed here may thus complete and stimulate the research on transformational leadership and team creativity.

In particular, our model may help to reveal the effects of transformational leadership on diverse organizational teams. Transformational leadership has only recently been investigated as a moderator of the diversity-performance relationship. Shin and Zhou (2007) confirmed that transformational leadership moderates the relationship between educational specialization diversity and team creativity. Under high levels of transformational leadership, the 
relationship between educational specialization diversity and team creativity was high rather than low. In their study on diversity in age, nationality, and education, Kearney and Gebert (2009) found both collective team identification and the elaboration of task-relevant information to mediate the relationship between diversity and team performance. Transformational leadership was confirmed to moderate the relationship between diversity and the mediators. Hüttermann and Boerner (2011) suggested in their conceptual paper that transformational leadership moderates between cross-functional diversity and conflicts. Our model provides an integrative framework for the existing approaches on the effects of transformational leadership in the diversity-team performance relationship. Thereby, we contribute to systematically link research on transformational leadership and research on workforce diversity.

\section{Implications for Further Research}

From the propositions developed in this article, hypotheses could be specified and tested empirically. More empirical investigations would contribute to the research on orchestras. To date, neither diversity nor the processes of idea generation and idea integration have been explored in the orchestra context. Moreover, transformational leadership has been studied only as an independent variable (Boerner and others, 2004; Boerner and von Streit, 2005), neglecting its possible moderating effects. Our model suggests a more comprehensive explanation of the effectiveness of transformational leadership in the orchestral context.

To address the model's limitations, further elaborations should include contingency variables such as musicians' skill and pay, the quality of their instruments, the acoustics of the premises, and so on. The model provides a starting point for research on the dual leadership model, that is, the interplay between artistic leadership and executive leadership in orchestras.

Measures to operationalize transformational leadership in the orchestras could be developed on the basis of existing research (Boerner and others, 2004; Boerner and von Streit, 2005). Similarly, scales to measure orchestral performance have been suggested and validated (Boerner and others, 2004; Boerner and von Streit, 2005). The degree of ensemble diversity could be operationalized by harking back to the literature on team diversity (for example, Blau, 1977). However, measures to capture the processes of idea generation and idea integration in the orchestral context would have to be developed.

Our suggested model could be used to examine the role of transformational leadership in contexts in which idea generation and idea integration are relevant moderators for organizational success and in which high levels of workforce diversity are common. Whereas measures for transformational leadership, team diversity, and team 
creativity are well established in the literature (for example, Kearney and Gebert, 2009; Zhou and George, 2001), scales for measuring the processes of idea generation and idea integration still must be developed. Although these processes can be well distinguished analytically, they might be entangled in practice. Therefore, it may be necessary to conduct qualitative studies to further elucidate these processes.

\section{References}

Antonakis, J., Bendahan, S., Jacquart, P., and Lalive, R. "On Making Causal Claims: A Review and Recommendations." Leadership Quarterly, 2010, 21(6), 1086-1120.

Atik, Y. "The Conductor and the Orchestra: Interactive Aspects of the Leadership Process." Leadership and Organization Development Journal, 1994, 15(1), 22-28.

Avolio, B. J., Walumbwa, F. O., and Weber, T. J. "Leadership: Current Theories, Research, and Future Directions." Annual Review of Psychology, 2009, 60, 421-449.

Bass, B. M. Leadership and Performance Beyond Expectations. New York: Free Press, 1985.

Bass, B. M., and Avolio, B. J. Improving Organizational Effectiveness through Transformational Leadership. Thousand Oaks, Calif.: Sage, 1994a.

Bass, B. M., and Avolio, B. J. "Introduction." In B. M. Bass and B. J. Avolio (eds.), Improving Organizational Effectiveness Through Transformational Leadership. Thousand Oaks, Calif.: Sage, 1994b.

Bass, B. M., and Riggio, R. E. Transformational Leadership. Mahwah, N.J.: Lawrence Erlbaum, 2006.

Blau, P. M. Inequality and Heterogeneity: A Primitive Theory of Social Structure. New York: Free Press, 1977.

Boerner, S. "Führung im Orchester: Ergebnisse der internationalen (empirischen) Forschung" [Orchestra Leadership: Results of International (Empirical) Research]. Das Orchester [The Orchestra], 2009, 11, 33-35.

Boerner, S., Krause, D., and Gebert. D. "Leadership and Cooperation in an Orchestra: An Empirical Study." Human Resource Development International, 2004, 7(4), 465-479.

Boerner, S., and von Streit, C. "Transformational Leadership and Group Climate: Empirical Results from German Symphony Orchestras." Journal of Leadership and Organizational Studies, 2005, 12(3), 31-41.

Cascio, W. F. "Whither Industrial and Organizational Psychology in a Changing World of Work?" American Psychologist, 1995, 50(11), 928-939.

Certo, S. T., Lester, R. H., Dalton, C. M., and Dalton, D. R. "Top Management Teams, Strategy and Financial Performance: A Meta-Analytic 
Examination." Journal of Management Studies, 2006, 43(4), 813-839.

Couch, S. R. "Patronage and Organizational Structure in Symphony Orchestras in London and New York." In B. J. Kamerman and R. Martorella (eds.), Performers and Performances: The Social Organization of Artistic Work. South Hadley, Mass.: Bergin, 1983.

Dumdum, U. R., Lowe, K. B., and Avolio, B. J. "A Meta-Analysis of Transformational and Transactional Leadership Correlates of Effectiveness and Satisfaction: An Update and Extension." In B. J. Avolio and F. J. Yammerino (eds.), Transformational and Charismatic Leadership: The Road Ahead. Amsterdam: JAI, 2002.

Eisenbeiss, S. A., van Knippenberg, D., and Boerner. S. "Transformational Leadership and Team Innovation: Integrating Team Climate Principles." Journal of Applied Psychology, 2008, 93(6), 1438-1446.

Erd, R. "Kunst als Arbeit: Organisationsprobleme eines Opernorchesters" [Art as Work: Organizational Problems of an Opera Orchestra]. Soziale Welt [Social World], 1987, 38(4), 437-459.

Faulkner, R. F. "Career Concerns and Mobility Motivations of Orchestra Musicians." Sociological Quarterly, 1973, 14(3), 334-349.

Feist, G. "The Influence of Personality on Artistic and Scientific Creativity." In R. J. Sternberg (ed.), Handbook of Creativity. Cambridge: Cambridge University Press, 1999.

Feist, G. J., and Gorman, M. E. "The Psychology of Science: Review and Integration of a Nascent Discipline." Review of General Psychology, 1998, 2(1), 3-47.

Firlus, T. "Führung: Demokratie in Dur. Das Orpheus Chamber Orchestra trifft alle Entscheidungen ohne Dirigent. Manager wundern sich, wie das geht" [Guidance: Democracy in Major Key. Orpheus Chamber Orchestra Makes All Decisions Without Conductor; Managers Surprised]. Wirtschaftswoche [Economic Week], Aug. 3, 2001.

Gebert, D., Boerner, S., and Kearney, E. "Crossfunctionality and Innovation in New Product Development Teams: The Dynamics of the Dilemmatic Structure and Consequences for the Management of Diversity." European Journal of Work and Organizational Psychology, 2006, 15(4), 431-458.

Gebert, D., Boerner, S., and Kearney, E. "Fostering Team Innovation: Why Is It Important to Combine Opposing Action Strategies?" Organization Science, 2010, 21(3), 593-608.

Glynn, M. A. "Innovative Genius: A Framework for Relating Individual and Organizational Intelligences to Innovation." Academy of Management Review, 1996, 21(4), 1081-1111.

Hamilton, B. H. and Nickerson, J. A. "Correcting for Endogeneity in Strategic Management Research." Strategic Organization, 2003, 1(1), 51-78.

House, R. J. "A 1976 Theory of Charismatic Leadership." In J. G. Hunt and L. L. Larson, Leadership: The Cutting Edge. Carbondale: Southern Illinois University Press, 1977. 
Hunt, J. G., Stelluto, G. E., and Hooijberg, R. "Toward New-Wave Organization Creativity: Beyond Romance and Analogy in the Relationship between Orchestra: Conductor Leadership and Musician Creativity." Leadership Quarterly, 2004, 15(1), 145-162.

Hüttermann, H., and Boerner, S. "Fostering Innovation in Functionally Diverse Teams: The Two Faces of Transformational Leadership." European Journal of Work and Organizational Psychology, 2011, 20(6), 833-854.

Jackson, S. E., Brett, J. F., Sessa, V. L., Cooper, D. M., Julin, J. A., and Peyronnin, K. "Some Differences Make a Difference: Individual Dissimilarity and Group Heterogeneity as Correlates of Recruitment, Promotions and Turnover." Journal of Applied Psychology, 1991, 76(5), 675-689.

Jackson, S. W., Joshi, A., and Erhardt, N. L. "Recent Research on Team and Organizational Diversity: SWOT Analysis and Implications." Journal of Management, 2003, 29(6), 801-830.

Jaussi, K. S., and Dionne, S. D. "Leading for Creativity: The Role of Unconventional Leader Behavior." Leadership Quarterly, 2003, 14(4-5), 475-498.

Judge, T. A., Woolf, E. F., Hurst, C., and Livingston, B. "Charismatic and Transformational Leadership: A Review and an Agenda for Future Research." Zeitschrift für Arbeits- und Organisationspsychologie [Journal of Work and Organizational Psychology], 2006, 50, 203-214.

Kark, R., and Shamir, B. "The Dual Effect of Transformational Leadership: Priming Relational and Collective Selves and Further Effects on Followers." In B. J. Avolio and F. J. Yammarino (eds.), Transformational and Charismatic Leadership: The Road Ahead. Amsterdam: JAI, 2002.

Kark, R., Shamir, B., and Chen, G. "The Two Faces of Transformational Leadership: Empowerment and Dependency." Journal of Applied Psychology, 2003, 88(2), 246-255.

Kearney, E., and Gebert, D. "Managing Diversity and Enhancing Team Outcomes: The Promise of Transformational Leadership." Journal of Applied Psychology, 2009, 94(1), 77-89.

Keller, R. T. "Transformational Leadership and the Performance of Research and Development Project Groups." Journal of Management, 1992, 18(3), 489-501.

Keller, R. T. "Transformational Leadership, Initiating Structure, and Substitutes for Leadership: A Longitudinal Study of Research and Development Project Team Performance." Journal of Applied Psychology, 2006, 91(1), 202-210.

Milliken, F. J., and Martins, L. L. "Searching for Common Threads: Understanding the Multiple Effects of Diversity in Organizational Groups." Academy of Management Review, 1996, 21(2), 402-433.

Mintzberg, H. "Covert Leadership: Notes on Managing Professionals." Harvard Business Review, Nov. 1, 1998, 140-147.

Mohammed, S., and Angell, L. C. "Surface- and Deep-Level Diversity in Workgroups: Examining the Moderating Effects of Team 
Orientation and Team Process on Relationship Conflict." Journal of Organizational Behavior, 2004, 25(8), 1015-1039.

Reid, W., and Karambayya, R. "Impact of Dual Executive Leadership Dynamics in Creative Organizations." Human Relations, 2009, 62(7), 1073-1112.

Shamir, B., House, R. J., and Arthur, M. B. "The Motivational Effects of Charismatic Leadership: A Self-Concept Based Theory." Organization Science, 1993, 4(4), 577-594.

Sheremata, W. A. "Centrifugal and Centripetal Forces in Radical New Product Development Under Time Pressure." Academy of Management Review, 2000, 25(2), 398-408.

Shin, S. J., and Zhou, J. "When Is Educational Specialization Heterogeneity Related to Creativity in Research and Development Teams? Transformational Leadership as a Moderator." Journal of Applied Psychology, 2007, 92(6), 1709-1721.

Sosik, J. J., Kahai, S. S., and Avolio, B. J. "Transformational Leadership and Dimensions of Creativity: Motivating Idea Generation in Computer-Mediated Groups." Creativity Research Journal, 1998, 11(2), 111-121.

Turner, J. C. Rediscovering the Social Group: A Self-Categorization Theory. Oxford: Blackwell, 1987.

van Knippenberg, D., De Dreu, C.K.W., and Homann, A. C. "Work Group Diversity and Group Performance: An Integrative Model and Research Agenda." Journal of Applied Psychology, 2004, 89(6), 1008-1022.

van Knippenberg, D., and Schippers, M. C. "Work Group Diversity." Annual Review of Psychology, 2007, 58, 515-541.

Vredenburgh, D., and He, I. Y. "Leadership Lessons from a Conductorless Orchestra." Business Horizons, 2003, 46(5), 19-24.

Waldman, D. A., and Atwater, L. E. "The Nature of Effective Leadership and Championing Processes at Different Levels in a R\&D Hierarchy." Journal of High Technology Management Research, 1994, 5(2), 233-245.

Williams, K. Y., and O'Reilly, C. A. "Demography and Diversity in Organizations: A Review of 40 Years of Research." Research in Organizational Behavior, 1998, 20(S77), 77-140.

Yukl, G. A. Leadership in Organizations. Upper Saddle River, N.J.: Prentice Hall, 2006.

Zhou, J., and George, J. M. "When Job Dissatisfaction Leads to Creativity: Encouraging the Expression of Voice." Academy of Management Journal, 2001, 44(4), 682-696.

SABINE BOERNER is the chair of management, especially strategy and leadership, at the University of Konstanz, Germany.

DIETHER GEBERT is a professor at Renmin University of China, School of Business, Beijing. 